\section{PAULO FREIRE E O COMBATE AO ANALFABETISMO NA GUINÉ-BISSAU: A CAMPANHA NACIONAL DE ALFABETIZAÇÃO E EDUCAÇÃO DE ADULTOS}

\author{
PAULO FREIRE AND THE FIGHT AGAINST ILLITERACY IN GUINEA-BISSAU: THE \\ NATIONAL ADULT LITERACY AND EDUCATION CAMPAIGN
}
PAULO FREIRE Y LA LUCHA CONTRA EL ANALFABETISMO EN GUINEA-BISSAU: LA CAMPAÑA NACIONAL DE ALFABETIZACIÓN Y EDUCACIÓN DE ADULTOS

\section{Universidade Estadual do Rio Grande do Sul - Brasil}

\begin{abstract}
Resumo: O presente artigo foi elaborado no quadro das comemorações do centenário de Paulo Freire, grande educador brasileiro cujas contribuições vão para além do Brasil, chegando em vários países do continente africano entre eles a Guiné-Bissau. Neste país, Freire teve uma participação ativa na organização da nova educação almejada pelo país após a conquista da independência, notadamente na organização e execução da Campanha Nacional da Educação e Alfabetização de Adultos, uma das armas empreendidas na luta pela erradicação do analfabetismo. Trata-se de uma pesquisa de caráter qualitativo, tipo estudo de caso, descritivo, em que se observou, se registrou e se analisou essa contribuição. Constatou-se que apesar do grande empenho de Freire nessa campanha, a mesma não atingiu todas as expectativas pelo fato de entre outros não se ter uma língua de ensino apropriada para que a população tivesse condições de se apropriarem do saber; os conflitos político militares que assolaram o país, entre outros. Mesmo assim salienta-se que esta obra educacional deve ter continuidade por ser uma radialista, baseadas no encontro com o povo através do diálogo, enquanto instrumento metodológico que permite a leitura crítica da realidade, partindo da linguagem do povo, uma ferramenta de luta pela libertação dos oprimidos, um método de educação que valoriza o saber do povo e suas realidades culturais na construção de novos saberes emancipatórios.
\end{abstract}

Palavras-chave: Paulo Freire; Educação e Alfabetização de Adultos; Guiné-Bissau

\begin{abstract}
This article was elaborated within the framework of the centenary commemorations of Paulo Freire, a great Brazilian educator whose contributions go beyond Brazil, reaching several countries on the African continent, including Guinea-Bissau. In this country, Freire took an active part in organizing the new education sought after by the country after gaining independence, notably in the organization and implementation of the National Campaign for Adult Education and Literacy, one of the weapons undertaken in the struggle to eradicate illiteracy. This is a qualitative research, case study type, descriptive, in which this contribution was observed, registered and analyzed. It was found that despite Freire's great effort in this campaign, it did not meet all expectations due to the fact that, among other things, there is not an appropriate teaching language for the population to be able to appropriate knowledge; the political military conflicts that ravaged the country, among others. Even so, it should be noted that this educational work should continue for being a broadcaster, based on meeting the people through dialogue, as a methodological instrument that allows a critical reading of reality, starting from the language of the people, a tool for the struggle for liberation of the oppressed, a method of education that values the knowledge of the people and their cultural realities in the construction of new emancipatory knowledge.
\end{abstract}

Keywords: Paulo Freire; Adult Education and Literacy; Guinea Bissau 
Resumen: Este artículo fue elaborado en el marco de las conmemoraciones del centenario de Paulo Freire, un gran educador brasileño cuyas contribuciones van más allá de Brasil, llegando a varios países del continente africano, entre ellos Guinea-Bissau. En este país, Freire participó activamente en la organización de la nueva educación que buscaba el país después de su independencia, en particular en la organización e implementación de la Campaña Nacional de Educación y Alfabetización de Adultos, una de las armas emprendidas en la lucha por erradicar el analfabetismo. Se trata de una investigación cualitativa, tipo estudio de caso, descriptiva, en la que se observó, registró y analizó este aporte. Se encontró que a pesar del gran esfuerzo de Freire en esta campaña, no cumplió con todas las expectativas debido a que, entre otras cosas, no existe un lenguaje de enseñanza adecuado para que la población pueda apropiarse de los conocimientos; los conflictos político-militares que asolaron al país, entre otros. Aun así, cabe señalar que esta labor educativa debe continuar por ser un locutor, basado en el encuentro con las personas a través del diálogo, como un instrumento metodológico que permite una lectura crítica de la realidad, a partir del lenguaje de las personas, una herramienta para la Lucha por la liberación de los oprimidos, un método de educación que valora el conocimiento del pueblo y sus realidades culturales en la construcción de nuevos conocimientos emancipadores.

Palabras-clave: Paulo Freire; Educación y Alfabetización de Adultos; Guinea Bissau

\section{Introdução}

Pretende-se com o presente artigo, trazer, no quadro da comemoração do centenário de Paulo Freire, as contribuições deste grande educador brasileiro para a educação fora do Brasil, chegando em vários países do continente africano entre eles a Guiné-Bissau, em que, este grande educador teve uma participação ativa na organização da nova educação almejada pelo país após a conquista da independência, notadamente a Campanha Nacional da Educação e Alfabetização de Adultos, uma das estratégias empreendidas nos primeiros anos após a conquista da independência na luta pela erradicação do analfabetismo, uma das sequelas resultantes da dominação colonial.

A Guiné-Bissau é um pequeno país africano com uma superfície de $36.125 \mathrm{~km}^{2}$, localizado na costa ocidental do continente, fazendo fronteiras ao norte com o Senegal ${ }^{1}$, a este e sudeste com a República da Guiné Conacri e ao sul e oeste é banhada pelo Oceano Atlântico. Além da sua parte continental, o país compõe-se ainda de uma parte insular constituída principalmente pelo arquipélago de Bijagós, formado por mais de 50 ilhas e ilhéus, dos quais somente 17 são habitadas, e a população do país é estimada em 1,6 milhão de pessoas. Este território foi colônia portuguesa até 1974, ano em que se tornou independente após uma longa guerra de libertação, e ter declarado unilateralmente a independência em setembro de 1973.

Após a conquista da independência o governo guineense tomou uma série de medidas tendentes a reformar o sistema de ensino imposto ao país, com a intensão de, erradicar o sistema

\footnotetext{
${ }^{1}$ A Guiné Conacri e o Senegal foram colonizados pela França.
} 
colonial de ensino centrado nos meios urbanos, estranho, alienante, autoritário, discriminatório e elitista, para dar lugar a um novo sistema de ensino agora nacional, fundamentado nas experiências educacionais vivenciadas durante a luta de libertação nacional, onde a escola era combinada com o trabalho produtivo e com as condições de vida.

Na verdade, o sistema português de educação na Guiné-Portuguesa limitou-se durante muito tempo ao que os administradores coloniais enunciavam em dezembro de 1941: "ensinar o indígena a falar português e a rezar como os portugueses" ${ }^{2}$. Tratando-se da porcentagem de analfabetos, de acordo com Almeida (1981, p.40), entre as colônias portuguesas, a "Guine Portuguesa" apresentava maior índice $(98,85 \%)$, seguida por Moçambique $(97,86 \%)$, e depois Angola (96,97\%); e por último, Cabo Verde com $(78,50 \%)$.

Isso demonstra que o ensino colonial não só era totalmente inadaptado às realidades do país, como o contrariava e o destruia, não respondendo às necessidades de desenvolvimento sócio-econômico e cultural, pois estava divorciado da comunidade. Na verdade, o foco principal da educação estava voltado para a escolarização das crianças de famílias portuguesas habitantes da então província ultramarina da Guiné Portuguesa.

Eis porque, ao longo dos anos, a prioridade da educação colonial estava voltada para criação de escolas nos centros urbanos mais importantes onde havia um número mais elevado de população europeia e civilizado, fator esse que acabou por determinar o critério da organização, localização e o funcionamento das escolas. Vários textos legais e declarações das autoridades da época, conforme Almeida (1981, p. 38), deixam claro o papel destinado aos africanos pelos colonizadores: “civilizar' significa tornar o africano 'útil a sociedade' (portuguesa)".

Desta feita, após a independência do país, a herança colonial para o setor, se identificou na taxa de analfabetismo na ordem de 90\%; uma rede escolar com apenas 418 escolas; professores em número insuficiente e algo deslocado da nova realidade sócio-cultural e política; uma gritante falta de manuais didáticos; conteúdos programáticos que nada tinham a ver com a realidade guineense; uma língua de ensino falada apenas por cerca de $10 \%$ da população. Enfim, um manancial de indicadores que comprometiam e condicionavam toda e qualquer pretensão progressista do novo país acabado de se formar Estado independente ${ }^{3}$.

Para fazer frente as perniciosas consequências da prática educacional herdadas, definiuse a reforma do setor educacional como uma das principais tarefas a implementar, tendo em

\footnotetext{
2 Fafali Koudawo,"Educação e Teorias de Desenvolvimento: O que HÁ de Novo" in: Soronda № 19, INEP, Bissau, jan. 1995, p.106.

${ }^{3}$ Reflexão sobre o Impacto da Assistência Sueca à Guiné-Bissau no scetor da Educação, Bissau, Dez. De 2000, p.11.
} 
conta que a educação era considerada como um dos pilares do processo emancipatório. Isto porque como já foi enaltecido, o ensino colonial ignorou totalmente as diferentes realidades do país, contrariando e atacando-as à medida que estas fossem ameaças aos interesses exploratórios da metrópole.

Era preciso, portanto, introduzir radicais mudanças no sistema de ensino colonial, ainda prevalecente com vista à democratização da educação, fazendo com que maior número de guineenses pudesse frequentar a escola eliminando-se progressivamente a segregação e estratificação social imposta pelo jugo colonial. E, uma das estratégias promovidas para erradicar o analfabetismo dentro de todo esse processo de mudanças programadas para o setor educacional do país, era a Campanha Nacional de Alfabetização e Educação de Adultos, considerada de extrema importância para erradicar o analfabetismo com a maior brevidade possível, em que a contribuição de Paulo Freire foi muito importante.

Desta feita, pretende-se neste artigo trazer, de forma muito sucinta, a contribuição do grande educador brasileiro, no planejamento, organização e implementação desta campanha posta em pratica logo nos primeiros anos da independência do país. Trata-se de uma pesquisa de caráter qualitativo, tipo estudo de caso, descritivo, em que se observou, se registrou e se analisou a contribuição deste grande educador.

\section{Antecedentes da Campanha Nacional de Alfabetização e Educação de Adultos: A educação nas zonas libertadas}

Durante a luta de libertação nacional, nas regiões libertadas da dominação colonial e administradas pelo $\mathrm{PAIGC}^{4}$, construiu-se, uma vida nova, tendo-se uma organização política sólida, uma organização administrativa em constante evolução, uma organização judiciaria consequente, uma economia em desenvolvimento, serviços sociais e culturais em funcionamento, nomeadamente, unidades de saúde e escolas nas aldeias (internatos e semiinternatos) funcionando, e forças armadas treinadas, equipadas conscientes de suas responsabilidades, enquanto garantia da defesa e segurança do novo país em construção.

Ou seja, o partido (PAIGC), tinha a intensão de construir um Estado que não fosse reprodutor da sociedade tradicional, enraizada nas formas retrógradas de discriminação na base da etnia ou tribo, assim como na forma colonial elitista de cunho capitalista. Pretendia-se portanto eliminar as estruturas de opressão e exploração coloniais e prosseguir a luta contra o

${ }^{4}$ PAIGC - Partido Africano da Independência da Guiné e Cabo Verde. 
colonialismo e o imperialismo construindo-se um Estado em que se garanta justiça, paz, igualdade e o progresso para o povo da Guiné-Bissau.

É importante frisar neste sentido que o PAIGC, logo que iniciou a luta armada de libertação nacional no ano de 1963, já tinha em seu controle algumas áreas da Guiné e, com isso foi possível colocar em prática alguns desses pontos, a partir da criação de escolas nessas localidades, tendo se expandido com essa iniciativa, sucessivamente com o avanço vitorioso da luta de libertação nacional.

Formalmente, esta medida foi definida em 1964, no primeiro Congresso deste partido conhecido pelo nome de "Congresso de Cassacá" " realizado de 13 a 17 de fevereiro em Cassacá, uma das localidades então libertadas do domínio português. Neste Congresso definiu-se, em linhas gerais, as características do novo modelo educacional que tinha como foco a formação de um novo homem e de uma nova mulher guineense, capaz de manter uma luta consequente para a descolonização total do país.

O programa maior do PAIGC, elaborado naquele período acentuava a necessidade de reformar e reconstruir o sistema educativo, para adequá-lo à realidade social e cultural das populações locais, tendo este novo sistema educativo se transformado em um alicerce para a contínua evolução e desenvolvimento desta população. Entre os pontos mais importantes do programa definidos na ocasião para a educação, destacam-se os seguintes:

1. Reforma do ensino, desenvolvimento do ensino secundário e técnico, criação do ensino universitário e de institutos científicos e técnicos.

2. Liquidação rápida do analfabetismo. Instrução primária obrigatória e gratuita. Formação e aperfeiçoamento urgente de quadros técnicos e profissionais.

3. Liquidação total dos complexos criados pelo colonialismo, das consequências da cultura e exploração colonialistas.

4. Na Guiné, desenvolvimento das línguas nativas e do dialeto crioulo, com criação da escrita para essas línguas. [...] Proteção e desenvolvimento da literatura e das artes nacionais.

5. Aproveitamento de todos os valores e conquitas da cultura humana e universal ao serviço dos povos da Guiné e Cabo Verde. Contribuição da cultura destes povos para o progresso da humanidade em geral (ALMEIDA, 1981, p. 58-59).

\footnotetext{
${ }^{5}$ O Congresso foi realizado a uma distância de mais ou menos 15 quilômetros de "Como", lugar onde ocorria a batalha contra a tropa portuguesa pela conquista desta ilha. O Congresso tinha como principais objetivos: 1-) Organizar as atividades políticas e armadas do partido, entre as quais a aprovação do programa do partido e a criação da Força Armada Revolucionária do Povo - FARP; 2-) Discutir como administrar as regiões que estavam sendo libertadas, sobretudo no que dizia respeito à educação, saúde, defesa e segurança e abastecimento alimentar; 3-) Corrigir os erros cometidos por alguns dirigentes do partido contra as populações e punir os respectivos infratores.
} 
Nota-se que os pontos 3 e 4 do programa, acima descrito, referem-se mais diretamente à situação de dominação cultural vivenciada pelos guineenses. Isto porque o partido tinha ciência de que a liquidação do "complexo de inferioridade" frente aos colonizadores seria um grande desafio, uma decisiva etapa da luta pela independência, pois, conforme a análise de Cabral, a cultura é a própria base do movimento de libertação e só as sociedades que conseguem preservar sua cultura podem se mobilizar e lutar contra a dominação estrangeira.

O partido entendeu que a sua principal arma seria o combate ao analfabetismo, ao obscurantismo, por ser esta a principal arma utilizada pelo colonizador para continuar a sua dominação e exploração. Desta feita, logo no início da luta de libertação, enquanto os colonialistas portugueses tentavam reformular o seu modelo escolar, como estratégia de manutenção da dominação colonial, surgia uma nova organização da educação e ensino nas zonas que se encontravam fora do domínio político-administrativo português, controladas pelo PAIGC, conhecidas por Zonas Libertadas. Estavam a ser lançadas, ali, as bases de um novo sistema de educação e formação orientado fundamentalmente para as necessidades de organização da população para a luta contra o colonialismo e para os ideais da nova sociedade que estaria emergindo.

Justificando a necessidade de se promover uma nova educação para a Guiné-Bissau, Varela (2011, p. 10-11) descreve alguns traços característicos da educação colonial do ponto de vista de Amílcar Cabral ${ }^{6}$ :

Toda a educação portuguesa deprecia a cultura e a civilização do africano. As línguas africanas estão proibidas nas escolas. O homem branco é sempre apresentado como um ser superior e o africano como um inferior. As crianças africanas adquirem um complexo de inferioridade ao entrarem na escola primária. Aprendem a temer o homem branco e a terem vergonha de serem africanos. A geografia, a história e a cultura de África não são mencionadas, ou são adulteradas, e a criança é obrigada a estudar a geografia e a história portuguesa.

Significando que o modelo da "educação alternativa", que o PAIGC estava a implantar nas zonas libertadas da Guiné-Bissau, isto é, nas regiões que este partido libertou do controle dos portugueses no período da luta pela independência entre 1963 e 1973 seria uma forma de "resistência cultural", pois, com esse tipo de educação denominado de "educação libertadora", havia a pretensão de formar uma mulher e um Homem novo, livre de qualquer tipo de dominação, comprometido com o desenvolvimento da nova sociedade que se pretendia

\footnotetext{
${ }^{6}$ Amílcar Cabral - Fundador do PAIGC e principal líder da luta pela independência da Guiné e Cabo Verde.
} 
construir após a independência, sociedade essa que seria construída pelo povo, em função da prática social em que a educação e os educadores teriam um papel fundamental.

$\mathrm{Na}$ verdade, a transformação cultural promovida pelo PAIGC junto às populações nas zonas libertadas da Guiné-Bissau fazia parte de um plano de ação política orientada a “incorporar dimensões de autonomia e de afirmação completamente novas”, ou seja, a condição de colonizado devia ser superada por homens e mulheres transformados pela luta. Havia o propósito de fomentar a criação de indivíduos que superassem, pela organização política, sua condição de submissão cultural imposta pelo colonialismo, de modo que o "homem objeto" se tornasse o "homem sujeito" histórico.

Estava, assim, surgindo um novo tipo de educação, a denominada educação alternativa para as zonas libertadas do jugo colonial português. No ano de 1965, segundo Furtado (2005), para enaltecer a necessidade da aplicação do plano do desenvolvimento da educação, diretivas gerais eram enunciadas pela direção do partido. Davidson, citado por Furtado, transcreve algumas diretivas definidas nas palavras de Amílcar Cabral:

Para continuar a desenvolver vitoriosamente a nossa luta devemos: Criar e difundir a educação em todas as regiões libertadas. Escolha de jovens entre os 14 e 20 anos, de entre os que completaram pelo menos a $4^{\mathrm{a}}$ classe para os mandar prosseguir a sua educação. Oponham-se, sem violência, a todos os costumes preconceituosos, a todos os aspectos negativos das crenças e tradições do nosso povo.... Obriguem todos os membros responsáveis e dedicados do nosso partido a trabalhar diariamente no aperfeiçoamento da sua formação cultural [...] (FURTADO, 2005, p. 315).

Cabral defendia, segundo Namone (2014, p. 62-63) que "[...] a resistência cultural só podia nascer e dar certo através da educação". Para ele essa educação deveria ser uma "educação política e de massa", cuja finalidade seria a promoção da "emancipação humana" para que o cidadão pudesse valorizar a sua própria realidade cultural e não a cultura do colonizador e que, por isso mesmo, esta alternativa educativa deveria ser expandida à todas as zonas libertadas, tendo como principal tarefa a formação de "[...] um homem novo com espírito crítico e consciente da sua realidade social" (NAMONE, 2014, p. 62-63). Para o efeito, essa educação tinha que ter "[...] ligação com as atividades produtivas, sobretudo a agricultura" (NAMONE, 2014, p. 62-63), considerada a principal base para o desenvolvimento da GuinéBissau.

Igualmente, conforme Almeida (1981, p. 60), ressaltava-se que entre os objetivos gerais da educação do PAIGC, dever-se-ia desenvolver na população a concepção científica do mundo. O líder deste partido dizia aos militantes que eles mesmos deveriam dar o primeiro passo. 
Educar-nos a nós próprios, educar os outros, a população em geral para combater o medo e a ignorância, para eliminar a pouco e pouco a submissão diante da natureza e das forças naturais que a nossa economia ainda não dominou. Lutar sem violências desnecessárias contra todos os aspectos negativos, prejudiciais ao homem, que ainda fazem parte das nossas crenças e tradições.

Num seminário de quadros realizado em 1969 pelo PAIGC, Amílcar Cabral justificava para os seminaristas as razões de o partido priorizar a educação, indicando que,

Na Guiné, 97\% da população não podia ir à escola. A escola era só para os assimilados, ou filhos de assimilados, vocês conhecem a história toda, não vou contá-la outra vez. Mas é uma desgraça que o tuga pôs na nossa terra, não deixar os nossos filhos avançarem, aprender, entender a realidade da nossa vida, da nossa terra, da nossa sociedade, entender a realidade da África, do mundo de hoje. Isso é o obstáculo grande para o desenvolvimento da nossa luta, camaradas, obstáculo grande, dificuldade enorme para o desenvolvimento da nossa luta (CABRAL, 1974, p. 22).

Ou seja, o papel da educação seria não só para o desenvolvimento da luta de libertação, mas, sobretudo, contribuiria decisivamente para o surgimento de uma cultura nacional cujas raízes estariam assentadas nos aspectos positivos das diferentes culturas tradicionais, mas que incluiria também as conquistas da ciência e da cultura universal as adaptando às reais necessidades do país e da sua população.

A primeira escola do partido, foi um jardim de infância destinado inicialmente às crianças, sobretudo aos filhos dos dirigentes do partido e às crianças órfãs da guerra, em Conacri $^{7}$, que mais tarde foi transformada em escola-internato, criada em 1965 denominada de Escola-Piloto. Mas aos poucos, sobretudo após o Congresso de Cassacá, a rede de escolas das zonas libertadas começava a desenvolver-se na base de um plano pré-concebido que evoluía à medida que os avanços da luta e as condições materiais e financeiras o permitissem. Esse propósito era claro nas palavras de Amílcar Cabral:

Temos que melhorar cada dia o nosso ensino, os nossos internatos, a nossa Escola-Piloto. Isso também é a consolidação das nossas áreas libertadas; Embora a nossa Escola-Piloto esteja fora, faz parte das nossas áreas libertadas, porque recebe os melhores alunos das nossas escolas das áreas libertadas, está integrada no nosso sistema de ensino das áreas libertadas, e está fora porque aí temos melhores condições para podermos fazer nela aquele trabalho que queremos fazer nesta fase da nossa luta (CABRAL, 1974, p. 66).

\footnotetext{
${ }^{7}$ Capital da vizinha República da Guiné-Conacri (limite sul da Guiné) em que havia um regime revolucionário liderado pelo seu primeiro Presidente Sékou Touré. Este país representou sempre uma retaguarda segura para o PAIGC que ali tinha também o seu Secretariado Geral.
} 
Observa-se desta feita, que nas regiões libertadas, estava-se a organizar o embrião do Estado Nacional como administração, ensino, saúde, produção, defesa, etc. em funcionamento e geridos pelos representantes eleitos pela população. Os alunos e professores não estavam fora deste processo, em que a ligação entre ensino e vida comunitária era evidente pois, os estudantes construíam suas mesas e bancos, cavavam trincheiras para se abrigar das bombas e participavam ativamente nas plantações dos alimentos para a sustentação dos habitantes da aldeia, enquanto estudavam.

A direção do partido estava igualmente, preocupado em formar quadros políticos e militares de alto nível para o progresso da luta. Para o efeito, criou-se o Centro de Instrução Política e Militar, que tinha como principais atribuições, a organização e promoção de cursos para formação política; instrução militar e alfabetização. Todas as atividades desta instituição, segundo Furtado (2005, p.320), eram apoiadas por bibliotecas criadas, desde 1964, nas zonas libertadas e por órgãos de informação e comunicação, e, com apoio de "[...] três dezenas de professores, o centro acolheu, em 1972, cerca de duzentos jovens e adultos para formação, durante meses". Esta seria o início da educação voltada para os jovens e adultos como forma de acelerar e buscar levar a educação a toda a população e reduzir o elevado número de analfabetismo com a maior brevidade possível.

Enfim, Cabral atribuía à educação ou, como ele sempre dizia, a "arma da teoria", grande relevância para a compreensão e a transformação da realidade política, social e cultural dos povos da Guiné-Bissau e Cabo Verde, que na sua compreensão, não culminaria com a mera proclamação formal da Independência, mas deveria prosseguir com vistas à plena emancipação do homem, com a remoção de todos os obstáculos, de todas as barreiras ao seu livre desabrochar e desenvolvimento, a conquista da verdadeira independência.

\section{A Campanha Nacional de Alfabetização e Educação de Adultos: Aspectos Gerais}

Após a conquista da independência política da Guiné-Bissau a principal tarefa do setor educacional se caracterizou pela busca de uma autonomia do país no sentido de criar um sistema educacional que tivesse como base as raízes culturais e sociais do povo guineense. Visava-se, sobretudo, aliar o trabalho manual ao intelectual, como forma a evitar o divórcio entre a escola e a comunidade e conciliar os valores culturais africanos com os conhecimentos, a ciência e a técnica das sociedades modernas.

Neste quadro, conforme Macedo (1978, p. 21-22), o então Comissário da Educação Nacional e Cultura, Mário Cabral, ao falar dos objetivos do ensino defendeu que as 
transformações do ensino da Guiné-Bissau deveriam orientar-se no sentido da viabilização dos seguintes objetivos:

$1^{\circ}$ - Concretizar o direito de cada um à educação e ao saber, dando a todos as mesmas oportunidades através das seguintes medidas: a) eliminar as disparidades entre a cidade e o campo e desenvolver as vocações regionais; b) fazer participar toda a população na ação educativa sob todas as formas; c) repartir equitativamente os recursos disponíveis para a educação.

$2^{\circ}$ - Criar um sistema educativo que, favorecendo particularmente o desenvolvimento dos valores culturais nacionais, saiba transmitir igualmente os valores universais necessários ao desenvolvimento individual e coletivo traduzindo-se pela: a) revalorização do património nacional; b) adaptação dos programas e dos métodos de educação ás realidades e ás necessidades da nação; c) procura de melhor adequação entre o sistema educativo e a estratégia de desenvolvimento socioeconômico (a formação recebida deve permitir a cada um, a todos os níveis, inserir-se no circuito da produção).

Salienta-se igualmente a necessidade de se instaurar um sistema de formação continuada para garantir o aperfeiçoamento das atividades profissionais e a produção industrial.

Uma das orientações gerais nesta fase era a de se reaproveitar todo o material patrimonial deixado pelos colonizadores portugueses, que não fosse prejudicial à mudança desejada. Foi assim que, os antigos quartéis portugueses se transformam em escolas, hospitais, hospedarias, de acordo com as necessidades evidenciadas. A própria língua portuguesa, com todas as implicações da ideologia da dominação colonial ainda prevalecente, foi escolhida corno língua oficial da Guiné-Bissau, considerada como elo com o mundo exterior, mesmo sendo compreendida e falada por poucos.

Evidentemente, o combate ao analfabetismo tornou-se uma das prioridades do desenvolvimento do país e a alfabetização como um processo de educação permanente, de formação da consciência política das massas que devia superar os limites da simples aprendizagem da leitura e da escrita, uma das ações empreendidas nesta luta.

É no quadro desta frente que se criou em 1975 o Departamento de Educação de Adultos ${ }^{8}$ (DEA) pelo Comissariado de Estado da Educação Nacional ${ }^{9}$, para entre outras tarefas, planejar, orientar e supervisionar todas essas atividades e lançar no ano de 1976 a Campanha Nacional de Alfabetização e Educação de Adultos.

\footnotetext{
${ }^{8}$ DEA: Departamento de Educação de Adultos.

${ }^{9}$ Nomenclatura do então Ministério de Educação.
} 
Alfabetizar não deve consistir apenas na aquisição da técnica da leitura, mas deve ser um meio de conscientização política das massas. $\mathrm{O}$ processo de alfabetização deve ser continuado e aprofundado através da capacitação técnica e profissional dos alfabetizandos e sua inserção na comunidade. A alfabetização deve apoiar-se em todas as iniciativas a realizar pelos diferentes sectores da vida nacional empenhados na promoção e desenvolvimento das comunidades e em todas as iniciativas do PAIGC destinadas a elevar o nível da consciência política do nosso povo e incentivar a sua participação activa, criadora e crítica na Reconstrução Nacional. O analfabetismo deve ser combatido como entrave ao desenvolvimento económico e social. (PEREIRA, 1977, p. 115).

Tendo ciência dos desafios a enfrentar e a falta de meios, a campanha foi sendo realizada em articulação com o ensino formal, como uma necessidade para a democratização do ensino e evitar a duplicação de ações e com isso buscar a eficácia e a economicidade na aplicação dos recursos disponíveis, dado que ambos buscavam os mesmos objetivos. Foi a partir desta visão integrada que, durante algum tempo, permitiu-se, por exemplo, a formação conjunta de docentes nos centros criados pelo Comissariado de Estado da Educação Nacional.

Essa alfabetização passou por diversas experiências e reformulações nesses primeiros anos, enfrentando inúmeras dificuldades num país onde quase a totalidade da população não falava ou entendia a língua oficial, o português e mais de $90 \%$ dos adultos eram analfabetos; onde coexistiam mais de 20 línguas e dialetos étnicos sem escrita e a língua de ligação o crioulo, considerada a língua nacional falada, sobretudo pelos moradores dos centros urbanos, sem uma escrita ou codificação reconhecida.

Para levar adiante esta atividade, o Comissariado da Educação Nacional contava com o apoio de uma equipe de consultores do IDAC - Instituto de Ação Cultural ${ }^{10}$ sediado na época em Genebra, na Suíça, liderada pelo educador brasileiro Paulo Freire então consultor junto do Gabinete de Educação do Conselho Mundial de Igrejas, convidado para prestar consultoria na implantação desta Campanha Nacional de Alfabetização, nomeadamente na concepção, conscientização e orientação da alfabetização, como um processo sócio-político, em que a aprendizagem da escrita poderia, no limite, ser secundaria:

[...] a consciencialização, associada ou não ao processo de alfabetização (pouco importa), não pode ser um "bla-bla-bla" alienante, mas sim um esforço critico de pôr a claro a realidade, o que implica, necessariamente, um compromisso político. Não existe consciencialização se a prática não nos leva à acção consciente dos oprimidos como classe social explorada na luta pela libertação. Por outro lado, ninguém consciencializa ninguém. O educador e o povo consciencializam-se através do movimento dialético entre a reflexão crítica da acção que se segue no processo dessa luta. (FREIRE, 1978, p. 17).

${ }^{10}$ IDAC: Instituto de Ação Cultural. 
Por isso mesmo, conforme Freire (1978) a educação-libertação não é um simples método aplicável pelos peritos. Ela constitui um todo que não pode ser reduzido a técnicas assexuadas, desligadas de um contexto de confronto social:

A educação para a liberdade não reduz-se a libertar os educandos do uso do quadro negro para oferecer-lhes projetores de diapositivos. Pelo contrário, propõe-se como práxis social, contribuir para a libertação dos homens da opressão a que se encontram submetidos, no seio da realidade objectiva. Tratase de uma educação política, tão política, como a outra que posta ao serviço das elites do poder, pretende, contudo proclamar-se neutra. É por esta razão que esta educação não pode ser traduzida na prática, em termos sistemáticos, antes da transformação radical da sociedade. Seria realmente uma ingenuidade que só os "inocentes" podem ter, esperar que as elites do poder estimulem um tipo de educação que revela o seu "jogo", mais claramente do que as contradições em que se encontram envolvidos. Esta ingenuidade implicaria, inclusivamente, uma perigosa subestimação da capacidade e da astúcia das elites. Por isso esta forma de educação apenas pode ser praticada fora do sistema regular, por aqueles que, superando a sua inocência, se comprometem cautelosamente no processo de libertação real. (FREIRE, 1978, p. 17-18).

Paulo Freire (1978) considerava que a educação pode contribuir para a construção de uma cultura nacional popular e defendia neste sentido que o povo guineense deveria conquistar a sua palavra, afirmando que:

Na perspectiva libertadora, que é a da Guiné-Bissau, que é a nossa, a alfabetização de adultos, (...) é a continuidade do esforço formidável que seu povo começou a fazer, há muito, irmanado com seus líderes, para a conquista de sua palavra. Daí que, numa tal perspectiva, a alfabetização não possa escapar do seio mesmo do povo, de sua atividade produtiva, de sua cultura, para esclerosar-se na frieza sem alma de escolas burocratizadas em que cartilhas elaboradas por intelectuais distantes do povo - em que pese às vezes sua boa intenção - enfatizam a memorização mecânica a que antes me referi. (FREIRE, 1978, p. 91).

Foi esta dialética da autolibertação que, seduziu os dirigentes do PAIGC, ao ponto de solicitarem o concurso deste educador para ajudar a construir este pretendido projeto de alfabetização de massas na Guiné-Bissau, nestes primeiros anos de independência. Era na verdade uma admiração dos dois lados, pois Paulo Freire era também um admirador dos escritos de Amílcar Cabral e da própria luta de libertação de um país que aprendeu a conhecer apenas após a sua independência enquanto consultor educacional encontrando ali um terreno favorável à educação-libertação,

[...] cujo povo direta e indiretamente tinha sido tocado pela guerra de libertação "um facto cultural e um fator cultural" na expressão de Amílcar Cabral, e cuja consciência política tinha sido partejada pela luta mesma. Um povo que, apresentando um alto índice de analfabetismo, 90\%, do povo, do ponto de vista linguístico, é altamente letrado "letrado" do ponto de vista 
político, ao contrário de certas "comunidades" sofisticadamente letradas, mas grosseiramente "analfabetas" do ponto de vista político. (FREIRE, 1978, p. 17-18).

Nota-se com isso que o pensamento de Freire coincidia com as diretrizes do PAIGC formuladas por Amílcar Cabral durante a luta pela independência da Guiné: Construir um sistema educativo que teria como finalidade, criar uma educação de massas que permitisse a integração do povo no mundo moderno, com igualdade de oportunidades para todos os cidadãos.

De acordo com Freire (1978) a alfabetização deve contribuir para o aclaramento da consciência política da população e que por isso, esta não deve de forma alguma ser pensada isoladamente como um conjunto de técnicas e métodos, mas, ao contrário, ela deve estar inserida no projeto cultural que por sua vez estaria atrelado a objetivos políticos e econômicos. Ou seja, a alfabetização assim como o projeto cultural deve estar de acordo com o projeto de sociedade que se pretendia construir para o novo país.

Por conseguinte, os objetivos da alfabetização de adultos definidos pelo Comissariado de Educação Nacional eram os seguintes:

1. Transmitir o máximo de conhecimentos a todo o povo, de forma a torná-lo elemento ativo das transformações sociais;

2. Levar as massas populares a compreender o que devem fazer para sua terra e quais os objetivos que ele já conhece na prática;

3. Valorizar o trabalho do povo, levando-o ao conhecimento do papel ou função daquelas coisas que ele já conhece na prática;

4. Valorizar o homem e aproveitar as suas capacidades criadoras, de maneira que o nível de todo o povo seja modificado e gradualmente melhorado; e,

5. Criar uma sociedade em que os homens possam exercer verdadeiramente a sua personalidade e criar um desenvolvimento em que toda a potencialidade do povo seja posta a serviço do homem.

Para cumprir com esta missão a alfabetização deveria ser completa, ou seja, englobar todos os aspectos de desenvolvimento e da vida das populações como, por exemplo, a saúde, enfocando assuntos como a questão da prevenção e o combate dos mosquitos, por exemplo; a importância do trabalho coletivo em contraposição ao trabalho individual o que poderia estimular, por exemplo, a criação de cooperativas agrícolas; e deveria ser executada tanto na cidade como no campo, buscando a transformação da realidade social em que vive a população e a erradicação dos ideais implantados pela colonização, valorizar a cultura local e criar uma identidade nacional. 
Para iniciar as atividades da Comissão Coordenadora dos Trabalhos de Alfabetização de Adultos, Freire e sua equipe fizeram algumas visitas de trabalho ao Comissariado de Educação Nacional. A primeira tinha a ver com a aprovação das bases do convênio entre o Conselho Mundial de Igrejas e o Governo da Guiné-Bissau, delinear como seriam efetivados os seminários de avaliação do trabalho a ser desenvolvido por Freire e sua equipe em Genebra assim como a implantação do programa de atividades que seria administrado pelo Comissariado de Estado da Educação Nacional e Cultura, junto com um membro do IDAC que se instalaria em Bissau, para trabalhar junto a Comissão Coordenadora.

Partíamos, pois de uma posição radical: a da recusa a qualquer tipo de solução 'empacotada' ou pré-fabricada; a qualquer tipo de invasão cultural, clara ou manhosamente escondida. A nossa opção política e a nossa prática em coerência com ela nos proibiam, também, de pensar sequer que nos seria possível ensinar aos educadores e educandos da Guiné-Bissau sem com eles aprender. (FREIRE, 1977, p. 17).

Nota-se aqui o entendimento de Freire de que as escolhas ou definições de todo o processo tinha que partir dos guineenses, conhecedores dos seus problemas e necessidades e que tanto ele como a equipe estava ali como apoiadores do processo e que para tal teriam que ensinar e aprender com a equipe local, com suas práticas e experiências educativas.

Neste primeiro encontro foram igualmente programadas algumas visitas que Freire e sua equipe fariam para entre outras ações, fazer avaliação das atividades realizadas na prática, assim como a sequência dos trabalhos e as bases das futuras visitas. De acordo com Freire (1977), em Genebra ele a equipe seguiriam analisando a questão da educação como um todo em especial em relação à campanha da alfabetização de adultos. Receberiam da parte da Comissão Coordenadora em Bissau a relação de materiais didáticos de que se precisa para as atividades a serem levadas a cabo e buscariam financiamento e aquisição desses materiais.

Dessa forma, nasceu o projeto que põe juntos, hoje, de um lado, o Comissariado de Educação da Guiné-Bissau, de outro a Commission on Churces' Participation in Development, que o financia, o Instituto de Ação Cultural e o Departamento de educação do Conselho Mundial de Igrejas.

Há um ano que, sempre em diálogo com os nacionais, prestamos a mínima contribuição que podemos, e de que vem resultando um aprendizado que nos enriquece a todos (FREIRE, 1977, p. 42).

A primeira iniciativa da equipe de Freire, para ter uma visão mais realista das atividades que estavam sendo realizadas neste processo de transformação do sistema de ensino e a montagem da nova prática educativa que estivesse consonante com o projeto da nova sociedade que se pretendia construir, foi o estabelecimento de contatos com todos os departamentos do 
Comissariado de Educação para assim ter ciência dos problemas enfrentados, sobretudo nos níveis de ensino primário e secundário e as soluções encontradas.

A alfabetização teria dois focos fundamentais, as Forças Armadas e a População Civil. No caso das forças armadas, desde os primórdios da luta de libertação, a Campanha de Alfabetização já era uma realidade, e buscava atender as necessidades da guerra, em que era necessário ensinar os militares a ler e a escrever para poderem manejar algumas armas consideradas sofisticadas. Mas, dadas às circunstâncias de guerra e a falta de meios para um trabalho de continuidade, não houve campanha sistemática e de grande envergadura voltada para a população civil.

Após a independência a campanha no seio das $\mathrm{FARP}^{11}$, foi reorganizada e sistematizada em 1975 pelo Comissariado de Estado das Forças Armadas. De acordo com Almeida (1981, p. 148), um só militante militar guineense participara de um seminário de formação de monitores em Lisboa, conhecendo o método de Paulo Freire. Ao regressar dessa formação, coordenou em Bissau "um curso de capacitação para membros das FARP, onde se formaram inicialmente 82 animadores e 7 supervisores". Com a sequência do trabalho foram formados mais 150 militantes armados.

Este projeto de alfabetização dividia-se em três fases: acabar com o analfabetismo nas Forças Armadas em Bissau; em seguida, enquanto na capital se inicia a pós-alfabetização, estendia-se a alfabetização a todos os quartéis do país; e após, os militantes das FARP alfabetizariam a população civil.

Salienta-se que as Forças Armadas guineenses constituíam um meio politicamente privilegiado, pois seus membros participaram da luta pela independência e a alfabetização tinha um propósito bem claro e entendido por todos: um instrumento para a aquisição de novos conhecimentos indispensáveis as suas novas tarefas na luta pela reconstrução do país, voltadas para a promoção do desenvolvimento do povo guineense.

Este entendimento fez com que em 1976, nos quartéis de Bissau tenha-se praticamente erradicado o analfabetismo e nos quarteis do interior do país $80 \%$ dos militantes das FARP estavam sendo alfabetizados. E, o fato de todos dominarem e falarem bem o crioulo, desde o período da luta de libertação facilitou a transição para o português (ALMEIDA, 1981).

No entanto, e ao mesmo tempo e para a alfabetização da população civil, o Comissariado de Educação Nacional tinha criado duas entidades: a Comissão Nacional de Coordenação de Alfabetização encarregada pela orientação política e a Comissão Nacional de Alfabetização -

${ }^{11}$ FARP: Forças Armadas Revolucionárias do Povo. 
$\mathrm{CNA}^{12}$ - responsável pelos aspectos técnicos, sendo estas duas entidades responsabilizadas pelas campanhas até 1978, quando foi criado o Departamento de Educação de Adultos.

A campanha de alfabetização nos bairros de Bissau foi a primeira atividade desta comissão e, para a sua realização o Comissariado da Educação fez um apelo aos professores dos estabelecimentos de ensino, estudantes e militantes da Juventude Africana Amílcar Cabral - JAAC ${ }^{13}$, para que participassem da alfabetização dos adultos cuja mobilização estava confiada aos Comitês de bairros.

O trabalho de alfabetização da população civil residente nos bairros de Bissau foi bem difícil. Essa população não participou ativamente da luta contra os colonizadores. O objetivo da alfabetização, para esses adultos (que saíram de suas tabancas em busca de uma vida mais segura em Bissau, onde encontraram péssimas condições de habitação e trabalho incerto), tinha um caráter individualista: candidatar-se a um emprego, melhorar de vida, mas através de esforços isolados e não, coletivos. (ALMEIDA, 1981, p. 149/150).

Este problema aliado ao fato da maioria desses adultos não falarem o crioulo e tampouco o português que era a língua utilizada nesse ensino (falavam, sobretudo as suas línguas étnicas em seu dia-a-dia), aumentava ainda mais a gama de dificuldades enfrentadas por essa alfabetização. Além disso, os alfabetizadores não foram preparados para essa atividade, seu trabalho pedagógico não estava apoiado em nenhuma experiência anterior, pois era a primeira vez que se realizava este tipo de alfabetização. E, por ser um trabalho voluntario, embora estivessem mobilizados para a tarefa, não estavam comprometidos com ela até porque estavam em geral com muitos outros afazeres junto aos seus locais de trabalho.

Por outro lado, o conteúdo da alfabetização segundo Almeida (1981), não estava ligado à realidade nem às necessidades cotidianas dos alfabetizados; o método não propiciava a reflexão e a discussão coletiva sobre temas de seu interesse; os objetivos de ascensão social não eram automaticamente atingíveis pela alfabetização. Em consequência, o trabalho pareceu sem sentido para aqueles que se esforçavam e não previam resultados satisfatórios. Esta situação acabou por provocar o esvaziamento dos grupos e aos poucos os monitores foram desistindo e assim a primeira tentativa de alfabetização da população civil foi mal sucedida.

Na sua primeira visita Freire constatou este fato salientado que enquanto a alfabetização de adultos realizada nos quarteis em Bissau tinha 82 círculos de cultura funcionando, a alfabetização de adultos para a população civil nos bairros populares da capital, estava praticamente paralisada, (FREIRE, 1977) "tudo estava por fazer ou refazer". Isso demonstra

${ }^{12}$ CNA: Comissão Nacional de Alfabetização.

${ }^{13}$ JAAC: Organização da juventude do PAIGC. 
que o processo de alfabetização de adultos, para servir ao desenvolvimento guineense, contribuindo para o esforço de construção de uma nova sociedade, teria de considerar a realidade quotidiana da população, visando seus problemas e desafios, suas necessidades e sua cultura e também acompanhar as transformações socioeconômicas que ocorriam no país.

\section{Organização e Principais Desafios da Campanha Nacional de Alfabetização e Educação de Adultos: As Contribuições de Paulo Freire}

Como já foi enaltecido, o país tinha duas iniciativas de alfabetização com a mesma finalidade em funcionamento sem uma concertação: o das forças armadas e o da sociedade civil. E, uma das tarefas da equipe de consultores liderada por Paulo Freire seria unificar estas experiências, respeitando as suas especificidades, com o intuito de criar uma só campanha que tenha uma maior eficiência e abrangência. Feita a unificação destas iniciativas, na Comissão Nacional de Alfabetização presidida pelo então Presidente do Conselho de Estado (Presidente da República) Luís Cabral, a iniciativa é posta oficialmente em prática sendo anunciada em dezembro de 1976 para todo o país, intitulada de Campanha Nacional de Alfabetização e Educação de Adultos.

Integrava a Comissão Nacional de Alfabetização, os Comissariados da Educação, que se responsabilizavam pelas questões pedagógicas de organização da campanha; o Comissariado da Informação, que tinha sob sua responsabilidade a difusão da campanha e mobilização da população através do uso do jornal e do rádio e demais meios de informação e comunicação; o Comissariado da Saúde, para ligar a alfabetização aos programas de educação sanitária; o Comissariado da Administração Interna, que daria apoio logístico e mobilizaria os comités locais; o Comissariado da Agricultura, com o qual a alfabetização estaria ligada auxiliando a implantação de cooperativas de produção e fazendas estatais; o Comissariado das FARP que possuía as melhores experiências dessa alfabetização; as estruturas do PAIGC e também as organizações de massas do partido como a JAAC, a União Democrática das Mulheres UDEMU $^{14}$ e os sindicatos, contando ainda com o apoio da UNESCO e do Conselho Mundial das Igrejas.

A este propósito Freire (1977) sublinha que o projeto de alfabetização de adultos no campo civil, deveria ser implementado primeiramente em regiões cujas relações sociais de produção estivessem em processo de mudança e no interior de órgãos da administração do Estado, como hospitais, correios e telégrafos, devendo ser assumida pelas pessoas visadas. E,

${ }^{14}$ UDEMU: União Democrática das Mulheres 
para que o mesmo tivesse êxito, deveria haver uma estreita relação de colaboração entre o Comissariado de Educação com os outros Comissariados do Estado, como por exemplo, os comissariados do Planejamento e da Agricultura, dado que as atividades de alfabetização seriam realizadas também para os trabalhadores desses setores.

[...] os projetos de alfabetização de adultos, no campo civil, deveriam concretizar-se, de um lado, naquelas áreas em que, de acordo com a política do Partido, realizada pelo Governo, certas alterações nas relações sociais de produção estivessem verificando-se ou por verificar-se, a curto prazo; de outro, no interior de órgãos da administração do Estado - hospitais, correios e telégrafos, oficinas de obras públicas, etc. - cujos servidores tivessem, na alfabetização, a introdução a outros conhecimentos, necessários ao cumprimento das novas tarefas impostas pela reconstrução nacional. (FREIRE, 1977, p. 34/35)

Nota-se que Freire defendia a massificação da alfabetização antecedida da criação das condições necessárias para tal. Ou seja, o projeto deveria ser implantado por etapas. O educador salienta a importância do debate sobre as situações existenciais, pois estas refletem o cotidiano dos educandos os problemas sociais existentes na comunidade conjuntamente com a definição do que é cultura e do que é natureza, buscando a compreensão dos alfabetizados de que, o que o homem transforma é cultura e que, por conseguinte, as situações cotidianas podem ser transformadas, posto que são produtos das interações humanas.

Neste quadro, Freire propõe três etapas interligadas e interdependes, como caminho ideal a ser seguido para que a campanha de alfabetização e educação de adultos tenha sucesso:

1. Deve-se iniciar a atividade com o "levantamento do universo vocabular" (FREIRE, 1974, p.112), como meio de entendimento, através do diálogo com os adultos envolvidos, quais seriam as suas preocupações, desejos, potencialidades, costumes, hábitos e estilos de vida e expressões próprias, de forma a encontrar um universo de palavras geradoras.

2. Na segunda etapa deve-se ordenar as palavras selecionadas consoante a sua complexidade fonética e devem refletir as práticas quotidianas e a realidade socioeconómica dos alfabetizados: “A criação de situações existenciais típicas do grupo com que se vai trabalhar" (FREIRE, 1974, P. 114). Isto porque segundo Freire, a leitura do mundo precede a leitura da palavra. Nas suas palavras "desde muito pequenos aprendemos a entender o mundo que nos rodeia”. Essa leitura do mundo pode ser ingénua ou crítica, devendo ter a educação como principal preocupação a promoção da leitura crítica do mundo, para suscitar a consciência crítica e nortear a ação para mudança. 
3. A terceira etapa seria o momento da elaboração das «fichas-roteiros», com a decomposição das famílias silábicas "correspondentes aos vocábulos geradores" (FREIRE, 1974, p. 115).

Infelizmente no caso da Guiné-Bissau estas etapas não foram definidas com os atores locais, mas impostas pelo governo baseando-se nas experiências adquiridas durante a luta de libertação, tendo, no entanto os animadores culturais autonomia para adaptar as palavras aos educandos dos círculos. Certamente a resistência da população na campanha de alfabetização tem a ver com a distância entre os objetivos desta com os reais problemas e interesses da população, o que acabou por prejudicar a consecução dos seus objetivos.

Freire procurava com esta metodologia fazer com que a aprendizagem da leitura e da escrita permitisse aos jovens e adultos envolvidos aprofundassem a leitura do mundo e a consolidação das suas intervenções nas práticas sociais, reconhecendo-os como coprodutores do seu saber a partir das suas experiências de vida e de seus saberes que seriam a base dessa educação.

Isto porque, conforme Freire (1978), o processo de libertação de um povo não se dá, em termos profundos e autênticos, se esse povo não reconquista a sua palavra, o direito de dizê-la, de «pronunciar» e de «nomear» o mundo. E que, portanto impor a língua do colonizador ao colonizado é uma condição fundamental para a dominação, não sendo por acaso que os colonizadores falam da sua língua como língua e da língua dos colonizados como dialeto.

Por isso mesmo este educador propôs que a alfabetização na Guiné-Bissau fosse realizada nas línguas maternas das populações locais, ou então, numa língua mais próxima à materna, que neste caso seria o crioulo. $\mathrm{O}$ autor esclarece a sua proposta indicando que o sentido mais exato da alfabetização parte de "aprender e escrever a sua vida em língua que se domina e sente-se à vontade, como autor e testemunho da sua história" (FREIRE, 1975, p. 8), significando isso que a educação não é um processo neutro, mas um ato político baseado no processo de dialogicidade entre formador e formandos no campo educativo.

Esta prática educacional não foi exercitada na Guiné-Bissau dado que no entendimento dos dirigentes do PAIGC, não seria viável visto que, assim como o crioulo, não havia nenhuma língua local em condições de ser utilizada para a educação. Não é por acaso que Cabral dizia que a língua portuguesa era uma das melhores coisas que os tugas (portugueses) nos deixaram, porque é uma língua de comunicação, das ciências e da tecnologia que podia ser utilizado também como instrumento de comunicação e de relacionamento com os outros povos a nível internacional. 
No início de suas atividades, a formação dos orientadores foi considerada a primeira tarefa da Comissão Coordenadora que para essa tarefa convocou os antigos professores do Ciclo Preparatório de Bissau, para se dedicarem exclusivamente à alfabetização, e um monitor das FARP. Estes alfabetizadores seriam igualmente educadores políticos, responsáveis, tanto pela pesquisa da realidade socioeconômica dos alfabetizados do círculo predefinido, quanto pelo conhecimento dos objetivos políticos do PAIGC, temas que seriam tratados durante a alfabetização. Freire (1996, p.21), apontava neste sentido que seria imprescindível (...) que "o formando desde o princípio da sua experiência formadora, se assuma como sujeito na produção de saber e se convença definitivamente de que ensinar não é transferir conhecimento, mas criar as possibilidades para a sua produção ou sua construção".

Esta alfabetização estaria voltada para o aprendizado da leitura e da escrita das palavras que faziam parte do cotidiano dos educandos, que seriam por isso, denominadas de palavras geradoras, sendo discutidas e, a partir de suas famílias fonéticas novas palavras seriam escritas. Com esta nomenclatura pretendia-se demonstrar que estas palavras além de gerarem o debate, gerariam a formação de novas palavras e, consequentemente, de novos conceitos. Por exemplo, a palavra geradora luta, após o debate no círculo sobre o que significa luta, para que luta, contra quem e a favor de que se luta, os educandos aprenderiam escrever esta palavra a partir das famílias fonéticas LA-LE-LI-LO-LU e TA-TE-TI-TO-TU, os educandos formariam novas palavras e, posteriormente, formariam frases. (FREIRE, 1996).

Foram organizadas Brigadas de estudantes em Bissau, oriundos de diversas regiões do país, que passaram por estágios de formação para atuarem como alfabetizadores nas férias, em seus locais de origem (Tombali, Cacheu, Buba, Oio, e Gabú, as primeiras áreas atendidas). Antes das férias, o estágio consistia em contatos na região com responsáveis do PAIGC, dos Comitês de Tabanca, professores das escolas locais, educadores sanitários e população em geral. Os professores e estudantes, em cada região, foram chamados a se integrarem no trabalho de alfabetização. Em Bissau, o estágio incluía visitas a unidades de produção e serviços públicos, além de trabalhos voluntários (na agricultura, no hospital de Bissau) e também a elaboração de jornais murais, projeções de slides e formação teórica.

Após a formação, duzentos jovens foram recrutados para tal tarefa que, durante as férias, participavam do trabalho no campo e conviviam com os camponeses e, no período da tarde, ensinavam os adultos a ler e escrever, assim como noções de educação sanitária, higiene e agricultura, que tinham aprendido no curso de formação. Outra tarefa, desempenhada pelos alfabetizadores era a formação de novos animadores nas aldeias que deveriam continuar com o trabalho educativo após o retorno dos estudantes. 
Saliento que a preocupação de Freire não se restringia apenas a alfabetização, mas também com a pós-alfabetização. Por isso mesmo traçava os contornos do processo de forma integrada:

Como a entendo, a alfabetização de adultos já contém, em si, a pósalfabetização. Esta continua, aprofunda e diversifica o ato de conhecimento de que se inicia naquela. Não são, pois, dois processos separados - um antes, o outro depois - mas dois momentos de um só processo social de formação. E este, não importa o nome que se lhe dê - educação, acção cultural, animação - implica sempre, na alfabetização também como na pós-alfabetização, numa certa teoria do conhecimento posta em prática. (FREIRE, 1978, p. 136).

Infelizmente, tanto em Bissau como nas zonas rurais a campanha não atingiu os seus propósitos conforme fora programado, sobretudo para a população civil. Várias experiências foram então levadas acabo para tentar salvaguardar o processo, como por exemplo, o foco na aprendizagem de técnicas ligadas ao desenvolvimento, à agricultura, a noções de saúde e de higiene no lugar do aprendizado da leitura e da escrita, mas mesmo assim os resultados não foram satisfatórios.

Entre as justificativas para a falta de êxito nas zonas rurais apontava-se entre outras, o fato do período escolhido para a campanha ter coincidido com o das chuvas, quando as famílias estavam envolvidas com as lavouras; o fato das populações de religião muçulmana estar no período de jejum, a falta de material didático e de infraestruturas; a falta de apoio técnico; a falta de pessoal qualificado; a falta de monitores; à falta de mobiliário apropriado como carteiras e quadro-negro e a questão de ordem política, etc.; mas o principal problema mesmo era sem dúvida a língua de alfabetização, o português que como já salientei, era desconhecida pelas populações em geral.

Freire aponta os possíveis motivos para os problemas enfrentados pela alfabetização da população civil em Bissau e para a concretização dos trabalhos realizados nas Forças Armadas:

Refiro-me ainda ao nível incipiente do trabalho de alfabetização de adultos nas áreas populares de Bissau. Em todos os depoimentos em torno do andamento deste trabalho notava-se quão distantes se achavam os seus resultados, dos alcançados no mesmo esforço, no interior das FARP. (...).

Não é de se estranhar, por isso mesmo, que esses militantes, percebendo a luta pela reconstrução nacional como uma continuação necessária daquela, percebam, também, em termos críticos, a necessidade de aprenderem a ler e escrever como uma forma de melhor servirem à reconstrução do país e não como um meio de instrumentar-se no sentido de satisfazer a interesses individuais (FREIRE, 1977, p. 167).

É uma demonstração de que os militares estavam conscientes de que a alfabetização não só lhes forneceria conhecimentos necessários para o desempenho das novas tarefas, mas 
também ajudaria na reelaboração das experiências passadas, tanto políticas como culturais para a aquisição de conhecimentos e instrumentos que os qualifiquem para as novas tarefas a desempenhar, tanto no interior das Forças Armadas, seja na perspectiva de sua reinserção no meio da sociedade civil.

Em geral, os que se inscreviam para a alfabetização nos círculos culturais civis em Bissau buscavam com esta formação uma forma de melhorar as condições profissionais, na expectativa de conseguirem emprego nas instituições públicas. Não havia uma preocupação em analisar a forma como seu aprendizado poderia corroborar para a construção da nova sociedade que se pretendia construir. Estes, entre outros fatores justificavam o abandono dos cursos e dos círculos de cultura que acabaram por fechar um por um por falta de alunos. Freire (1977) sustenta que mesmo não obtendo o resultado esperado o projeto foi válido na medida em que surgiram experiências frutíferas que inclusive ajudaram na reformulação da perspectiva adotada no projeto de alfabetização.

Dada a sua grandeza a campanha requeria uma adequada organização, a preparação atempada dos recursos humanos e a garantia dos meios materiais, financeiros e logísticos. Ou seja, o Governo deveria colocar à disposição do programa o seu poder e os recursos que fossem necessários para assim criar um clima favorável para este tipo de intervenções, e também ter o apoio, o envolvimento e o comprometimento das populações visadas.

Efetivamente, muitas dessas condições nomeadamente, organização, programação e preparação da ação tiveram uma deficiente consideração no planejamento da campanha, tendo estas fragilidades refletido em todos os aspectos de organização da campanha e na preparação dos recursos humanos necessários, afetando a previsão dos recursos materiais e dos suportes didáticos específicos "cuja insuficiência, quantitativa e qualitativa se fez sentir ao longo de toda a campanha de alfabetização; não permitiram o conhecimento do meio, levando à adopção de uma metodologia de alfabetização inadequada às realidades do campo e dos camponeses" (FURTADO, 2005, p. 353).

Apesar das problemáticas apontadas, houve alguns resultados positivos: A alfabetização foi um sucesso ao nível das forças armadas, em que houve uma maior implantação, e também nos locais de trabalho onde a língua portuguesa era conhecida e utilizada de forma prática para acesso aos documentos, às instruções, às publicações, o que permitiu a melhoria dos conhecimentos dos participantes. Foram igualmente relevantes em termos de educação cívica, os resultados obtidos na educação, conscientização e mobilização das populações para os problemas relacionados com a agricultura, a saúde, a participação nas ações visando a transformação do meio ambiente, a melhoria das condições de vida, entre outros aspectos. 
Salienta-se que a língua de ensino foi e continua a ser o maior obstáculo a ser transposto pela educação na Guiné-Bissau, pois, no caso da campanha de alfabetização, tendo o português como língua não foi possível transitar da fase da leitura e escrita de algumas palavras à de leitura e interpretação de pequenos textos, significando portanto, que não havia uma ligação entre pensamento-linguagem e realidade objetiva. Como dizia Paulo Freire, a alfabetização de adultos, bem como a educação em geral, não podem sobrepor-se à prática social de um determinado contexto social, devendo sim emergir dessa prática.

Salienta-se igualmente, que a realidade atual da Guiné-Bissau se difere muito dos primeiros anos da independência. Isto porque, devidos a vários fatores de varia ordem, o Estado não conseguiu criar as condições econômicas e sociais basilares para se ter uma educação independente e nacional. Ao longo destes seus 47 anos de independência política, o país sofreu uma permanente instabilidade política, havendo mesmo conflitos armados que enfraqueceram todos os esforços investido para se criar as condições econômicas e sociais indispensáveis para a sua afirmação como país soberano.

Em consequência, o país foi obrigada a se submeter as políticas ditadas pelas entidades financeiras internacionais, nomeadamente o FMI e o Banco Mundial, impondo programas de ajustamento estrutural entre outros, como condição para financiar seus programas de desenvolvimento, em que a educação não seria mais uma prioridade. Com isso, o Estado assume cada vez menos a sua responsabilidade com a escola pública se distanciando da sonhada educação libertadora desejada para um povo que vive lutando.

Observa que de algum tempo para cá, em muitos casos o financiamento da educação pública em várias localidades é feito pelas comunidades, nomeadamente os pais e encarregados de educação para assim manter as escolas em funcionamento. Acredita-se que as iniciativas comunitárias seriam de momento, a melhor alternativa para se prosseguir com a proposta educativa de Freire e Cabral incluindo a campanha de educação e alfabetização de adultos, focada no contexto local, seus problemas e desafios, para que a população local possa escolher entre outras possibilidades o uso da língua que melhor se adeque a realidade da comunidade, podendo ser a língua nativa, o crioulo e ou o português como língua de ensino.

\section{Considerações finais}

A Campanha de Alfabetização de Adultos como uma das principais ferramentas para combater o analfabetismo no país deve ser considerada ainda hoje, como uma das prioridades no campo educacional na Guiné-Bissau, dado que o analfabetismo ainda é uma realidade presente tanto nas cidades como e sobretudo no campo. 
O governo deve neste sentido, evidenciar esforço e definir novas metodologias, encorajar a população desmotivada com o fracasso das primeiras experiências, analisar e decidir qual será a língua de ensino mais adequada para permitir uma aprendizagem com sucesso, tendo em conta as reais necessidades e os aspetos culturais próprios dos vários grupos étnicos do país.

Para o efeito deve-se promover a participação da comunidade no debate a respeito da educação como um todo e de adultos em especial, buscando conhecer as suas necessidades e, em conjunto, discutir sobre os conteúdos concretos a serem tratados para que se possa realmente construir a educação liberadora nas palavras de Freire ou a arma teoria para Cabral, indispensáveis para a formação de um homem e de uma mulher nova, livre de qualquer forma de dominação, cidadãos que finalmente conquistariam a sua palavra, o direito de dizê-la, de «pronunciar»e de «nomear» o mundo.

Esta obra educacional em que a participação de Paulo Freire foi marcante, deve ser continuada por ser uma radialista, baseadas no encontro com o povo através do diálogo enquanto instrumento metodológico que permite a leitura crítica da realidade, partindo da linguagem do povo, uma ferramenta de luta pela libertação dos oprimidos, um método de educação que valoriza o saber do povo e suas realidades culturais na construção de novos saberes emancipatórios.

\section{REFERÊNCIAS}

ALMEIDA, Hilda Maria Ferreira. Educação e transformação social: formas alternativas de educação em país descolonizado. 1981. 239 p. Tese (Mestrado em Educação) -Fundação Getúlio Vargas, Rio de Janeiro, 1981.

CABRAL, A. PAIGC: unidade e luta Lisboa: Nova Aurora, 1974.

FREIRE, P. Educação como prática da liberdade. Rio de Janeiro: Paz \& Terra, 1974.

Pedagogia do oprimido. Porto: Afrontamento, 1975.

A mensagem de Paulo Freire: textos de Paulo Freire selecionados pelo INODEP. São Paulo: Nova crítica, 1977.

Pedagogia do oprimido. 17. ed. Rio de Janeiro: Paz \& Terra, 1978.

Pedagogia da autonomia: saberes necessários à prática educativa. São Paulo: Paz e Terra, 1996. 
FURTADO, Alexandre Brito Ribeiro. Administração e gestão da educação na GuinéBissau: incoerências e descontinuidades. 2005. 702 p. Dissertação (Doutorado em Ciências da Educação) -Universidade de Aveiro, Aveiro, 2005.

MACEDO, Francisco de. A Educação na República da Guiné-Bissau - O Passado as transformações no presente, as perspectivas do futuro. Braga: Editorial Franciscana, 1978.

NAMONE, Dabana. A luta pela independência na Guiné-Bissau e os caminhos do projeto educativo do PAIGC: etnicidade como problema na construção de uma identidade nacional. 2014. 120 p. Dissertação (Mestrado em Ciências Sociais) -Universidade Estadual Paulista Júlio de Mesquita Filho, Araraquara, 2014.

PEREIRA, Aristides. Relatório do C.S.L ao III Congresso do PAICG: Resolução Geral Estatutos, a Direção Eleita. Bolama: Imprensa Nacional, 1977.

SANÉ, Samba. A Educação na Guiné-Bissau: Perspectivas na atualidade. O ensino básico em questão. 2019. 330 p. Dissertação (Doutorado em Educação) - Uiniversidade Federal de Santa Maia, Santa Maria, 2019.

VARELA, Bartolomeu Lopes. A educação, o conhecimento e a cultura na práxis de libertação nacional de Amílcar Cabral. Praia: [S.n.], 2012. Disponível em:

https://www.academia.edu/1308254/A_educa\%C3\%A7\%C3\%A30_o_conhecimento_e_a_cul tura_na_pr\%C3\%A1xis_de liberta\%C3\%A7\%C3\%A3o_nacional_de_Am\%C3\%ADlcar_Ca bral. Acesso em: 20 set. 2018.

\section{SOBRE O AUTOR:}

\section{Samba Sané}

Natural da Guiné-Bissau; Doutor em Educação pelo Programa de Pós Graduação em Educação da Universidade Federal de Santa Maria - UFSM/RS - Brasil. Professor da Universidade Estadual do Rio Grande do Sul - UERGS. E-mail: sambasane@ hotmail.com

(iD https://orcid.org/0000-0003-0630-6599 